\section{Acute cholangitis secondary to a recently migrated cystic duct clip, 15 years after cholecystectomy}

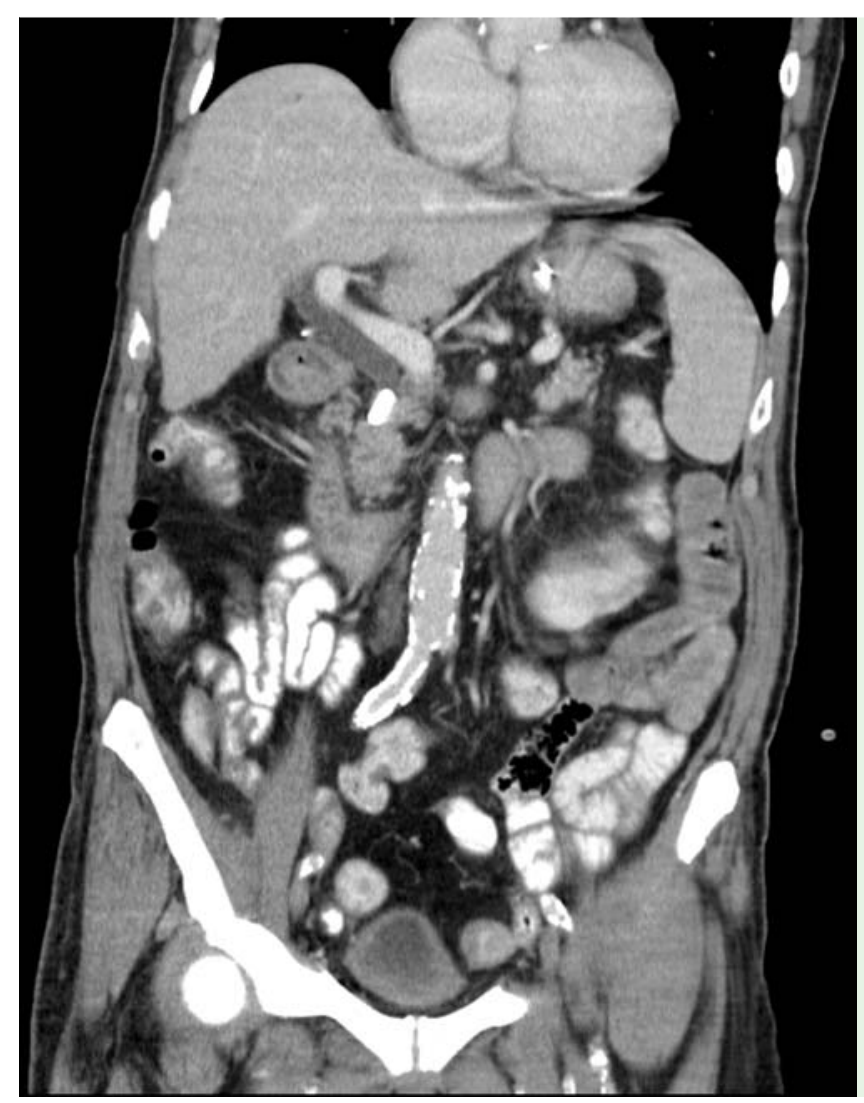

Fig. 1 Migrated surgical clip within the common bile duct.

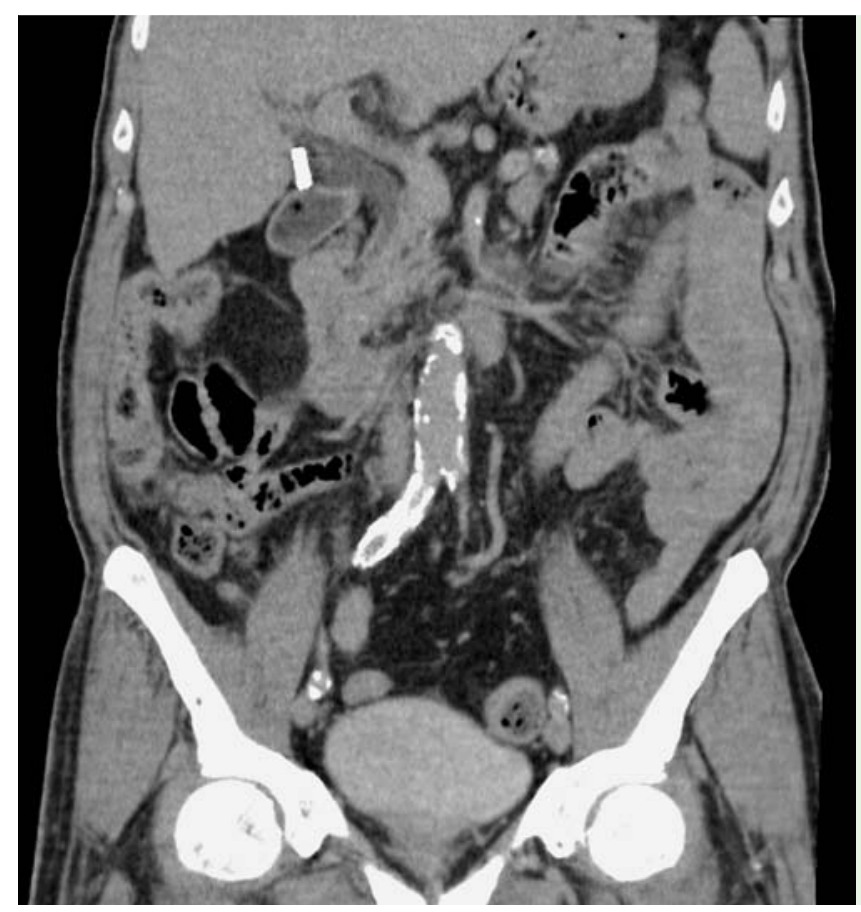

Following laparoscopic cholecystectomy, migration of surgical clips from the cystic duct stump into the common bile duct (CBD) is rare. We present a case of cholangitis secondary to a recently migrated clip, and successful treatment with endoscopic retrograde cholangiopancreatography (ERCP).

A 78-year-old man presented with fever and epigastric discomfort of 2 days' duration. He had previously undergone laparoscopic cholecystectomy in 1996. Investigations revealed the presence of Klebsiella bacteremia and obstructive jaundice. CT showed a migrated surgical clip within the distal CBD ( $\bullet$ Fig. 1). An earlier CT, 8 months before the present admission (during evaluation for gross hematuria), had shown the surgical clip to be situated correctly in the gallbladder bed/cystic duct stump region ( $\mathbf{F i g . 2}$ ). During ERCP, the clip was seen to be within the common bile duct ( Fig.3), causing mild CBD dilatation. Papillotomy was carried out, followed by clip extraction using a retrieval balloon (Extractor; Boston Scientific, Natick, Massachusetts, USA) ( Fig. 4, Video 1 ). The patient improved after the procedure, with resolution of jaundice and sepsis.

Surgical clip migration is a well-recognized complication of cholecystectomy. Most cases occur within 12 months after surgery, commonly presenting with obstructive jaundice, cholangitis, or biliary colic $[1,2]$. To date, the pathogenesis of clip migration remains unclear. Common hypotheses include the formation of biloma due to ineffective clipping and clip-induced local inflammation [2-5]. Later, the inflammatory process allows the clip to detach and erode into the neighboring CBD mechanically. In our patient, however, temporally separated CT images showed that the migration of the clip began more than a decade after the surgery, without biloma or inflammatory changes. Nonetheless, extraction of the clip from the CBD was easy via ERCP.

Endoscopy_UCTN_Code_CCL_1AZ_2AI

Competing interests: None

Video 1

Extraction of a migrated surgical clip from the common bile duct via endoscopic retrograde cholangiopancreatography. 

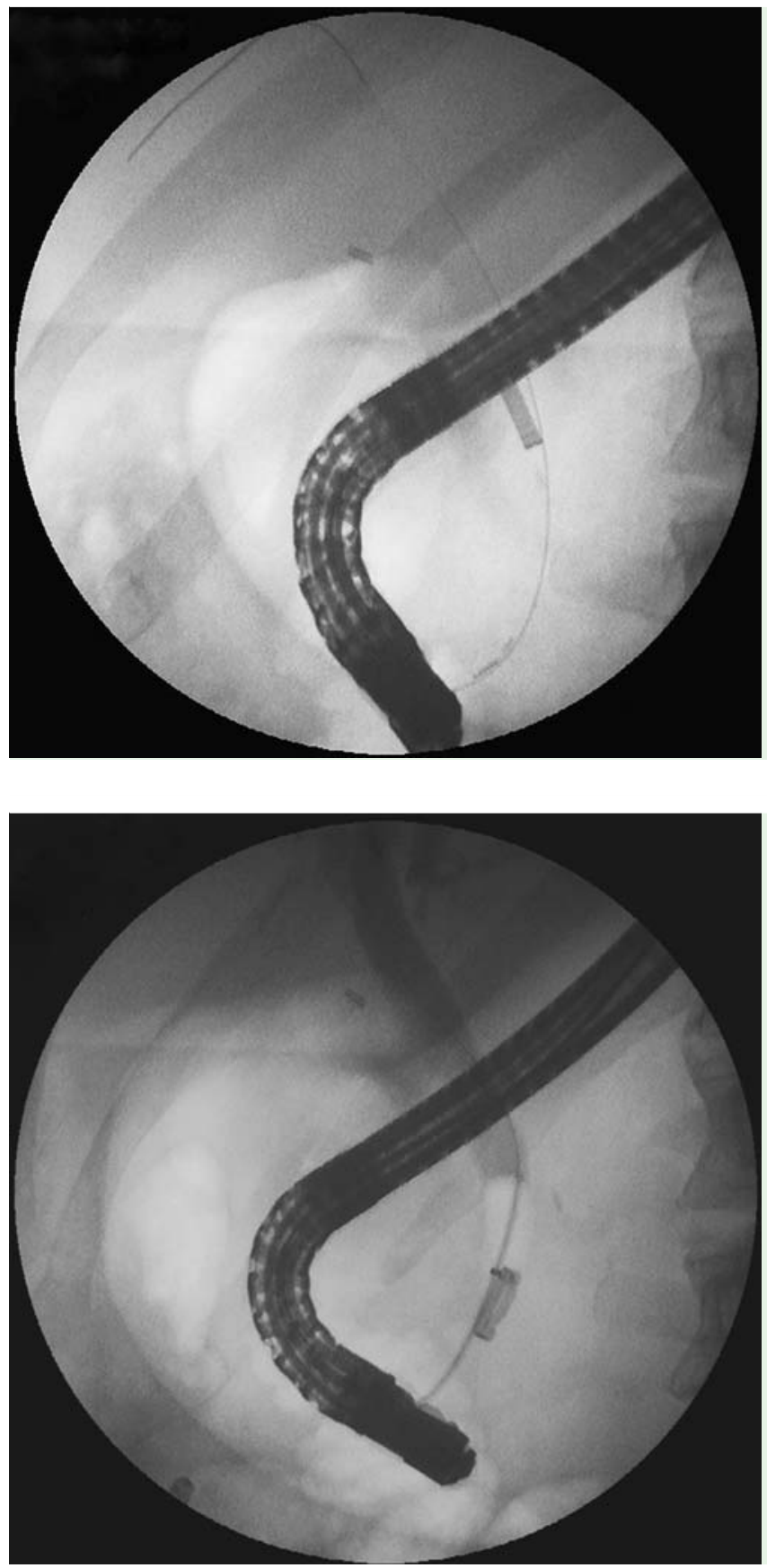

Fig. 3 Surgical clip within the common bile duct, seen during endoscopic retrograde cholangiopancreatography.

\section{Song, B. E. A. Kwek, T. L. Ang}

Department of Gastroenterology, Changi General Hospital, Singapore

\section{References}

1 Raoul JL, Bretagne JF, Siproudhis L et al. Cystic duct clip migration into the common bile duct: a complication of laparoscopic cholecystectomy treated by endoscopic biliary sphincterotomy. Gastrointest Endosc 1992; 38: $608-611$

2 Chong V, Chong C. Biliary complications secondary to post-cholecystectomy clip migration; a review of 69 cases. J Gastrointest Surg 2010; 14: 688-696

3 Goshi T, Okamura S, Takeuchi $H$ et al. Migrated endoclip and stone formation after cholecystectomy: a case treated by endoscopic sphincterotomy. Intern Med 2009; 48: 2015-2017

4 Chong VH, Yim HB, Lim CC. Clip-induced biliary stone. Singapore Med J 2004; 45: 533 535

5 Dolay K, Alis H, Soylu A et al. Migrated endoclip and stone formation after cholecystectomy: a new danger of acute pancreatitis World J Gastroenterol 2007; 13: 6446-6448

Fig. 4 Extraction of the surgical clip using a standard retrieval balloon.

\section{Bibliography}

DOI http://dx.doi.org/

10.1055/s-0032-1309914

Endoscopy 2012; 44: E294-E295

(c) Georg Thieme Verlag KG

Stuttgart · New York

ISSN 0013-726X

\section{Corresponding author}

\section{B. E. A. Kwek, MD}

Department of Gastroenterology

Changi General Hospital

2 Simei St 3

Singapore 529889

Fax: +65-67816202

andrewkwek@gmail.com

andrew_kwek@cgh.com.sg 